\title{
ENSINO DE ARTE E RURALIDADE: REFLEXÕES E APONTAMENTOS INTERCULTURAIS
}

\author{
Sérgio Naghettini ${ }^{17}$ \\ Universidade Federal de Uberlândia \\ sergionaghettini@yahoo.com.br
}

Resumo: Esse trabalho de pesquisa constitui um estudo de caso desenvolvido com base no estudo profundo do objeto de pesquisa referente à prática do professor no ensino da Arte como construção reflexiva e teórica em relação à proposição do fazer artístico vinculado à arte e cultura local. Uma prática que visa abordar e reconhecer a cultura local, sensibilizando os olhares dos discentes para situações diferenciadas das culturas locais em transformação e transição que ocorrem entre a cultura rural e urbana. Foi desenvolvida como projeto de pesquisa no Curso de Mestrado Profissional em Artes com o tema "Ensino da Arte e Ruralidade: reflexões e apontamentos interculturais". Espera-se que contribua para enriquecer as discussões para novas concepções práticas de ensino da Arte, numa proposta pedagógica de integração da arte, cultura e ruralidade. A pesquisa foi desenvolvida com base no estudo do objeto de pesquisa referente à prática do professor no ensino da Arte e tem como objetivo apreender e ressignificar reflexivamente o planejamento e o ensino de arte para discentes da zona rural mediante o propósito de subsidiar um ensino e aprendizagem cujo eixo central assenta-se na interculturalidade. Essa proposta de prática educativa para a escola rural procura relacionar o processo de educação com seu público alvo, discentes do $6^{\circ}$ ao $9^{\circ}$ anos, integrando as relações interculturais dos discentes nas aulas de Arte. Este estudo da prática docente em Arte constituiu um estudo de caso fundado na pesquisa etnográfica de orientação qualitativo-fenomenológica. Os procedimentos de coleta e análise de dados seguem a perspectiva da observação, do registro e da reflexão por meio de narrativas. Como forma de apresentar resultados, optei pela triangulação de procedimentos uma abordagem qualitativa, uma

17 Aluno do Mestrado PROF ARTES da Universidade Federal de Uberlândia, projeto em andamento 2017, área de estudo Abordagens teórico-metodológicas das práticas docentes, orientadora Prof. Dr. Elsieni Coelho da Silva, bolsista da CAPES e professor de Arte na rede municipal, Escola Municipal Emilio Ribas, Prefeitura Municipal de Uberlândia - PMU. 
metodologia etnográfica e método fenomenológico, resultante da observação típica de quem participam de sua prática. O processo investigativo da própria prática de ensino, na perspectiva etnográfica, envolve relação dinâmica de reflexão sobre si e com outro no processo de apreender a sua cultura, seus significados na concepção e desenvolvimento de práticas de ensino de Arte. A diversidade cultural e as interações culturais dentro do âmbito da sala de aula são complexas e diversas, possibilitando que o professor de Arte acolha em seus processos "toda a bagagem cultural e subjetividade" que os discentes trazem em suas expressões artísticas.

\section{INTRODUÇÃO}

Esse trabalho constitui um estudo de caso desenvolvido com base no estudo do objeto de pesquisa referente à prática do professor no ensino da $\operatorname{Arte}^{18}$ como construção reflexiva e teórica em relação à proposição do fazer artístico vinculado à arte e cultura local. Uma prática que visa abordar e reconhecer a cultura local, sensibilizando os olhares dos discentes para situações diferenciadas das culturas locais em transformação e transição que ocorrem entre a cultura rural e urbana. Foi desenvolvida como projeto de pesquisa no Curso de Mestrado Profissional em Artes com o tema "Ensino da Arte e Ruralidade: reflexões e apontamentos interculturais". Espera-se que contribua para enriquecer as discussões para novas concepções práticas de ensino da Arte, numa proposta pedagógica de integração da arte, cultura e ruralidade.

Escolher um problema e defini-lo num projeto de pesquisa, não foi uma tarefa fácil, visto que houve todo um percurso contextual transcorrido. A trajetória de estudos e análises propiciou o desenvolvimento do projeto, delineando uma forma de interação pessoal com o todo, ou seja, retomar meu percurso profissional de professor de Arte e pesquisador, retomar a história das práticas e reflexões de arte, rabiscos, linhas, curvas, formas e cores por meio das leituras e análises de escritores; consequentemente, retomar partes da minha vida pessoal que ajudaram a explicar como cheguei a essa dissertação, isto é, um trabalho da prática de professor de arte.

18 Neste trabalho de pesquisa, o termo "Arte" apresenta-se grafado com letra maiúscula quando se refere área como componente curricular, e com minúscula quando esta é área de conhecimento humano. 
Entendo que as experiências contribuíram para o sucesso do percurso e terá ecos durante toda a jornada da vida. Na obra Arte como Experiência, de John Dewey, ele descreve como a experiência aparece refletindo que

com frequência, entretanto, a experiência que se tem é incompleta. [...] Em contraste com tal experiência, temos uma experiência quando o material experienciado segue seu curso até sua realização. Então, e só então, ela é integrada e delimitada, dentro da corrente geral da experiência, de outras experiências. (DEWEY, 2010, p. 89).

Tendo como base a minha experiência como professor efetivo de Arte no ensino fundamental na Rede Municipal de Educação, há mais de 27 (vinte e sete anos), em escolas localizadas na zona rural e urbana de Uberlândia, observei, no decorrer de alguns anos, que o professor ao trabalhar com os referenciais culturais pode explorar a cultura local, a diversidade e a cultura erudita.

O aprofundamento das leituras propostas e pesquisas realizadas me conduziram ao objetivo da pesquisa, ou seja, apreender e ressignificar reflexivamente o planejamento e o ensino de arte para discentes da zona rural mediante o propósito de subsidiar um ensino e aprendizagem cujo eixo central assenta-se na interculturalidade.

Para cumprir tal proposição, os objetivos específicos desse trabalho de pesquisa são:

-apreender, por meio de um estudo de caso, as estratégias e propostas de ensino do professor em fundamentar, abordar, conhecer e perceber a interação das diferentes culturas que permeiam o espaço escolar dos discentes da zona rural de Uberlândia: -analisar as dimensões teórica/metodológicas na perspectiva da abordagem triangular ${ }^{19}$ na concepção e prática de ensino com enfoque na arte e cultura para alunos da zona rural;

- promover a ampliação de sentidos e significados da prática docente por meio de reflexões advindas da análise do estudo de caso;

\footnotetext{
${ }^{19}$ Abordagem triangular - De início denominada Metodologia Triangular, passou a ser chamada Proposta Triangular; agora Ana Mae Barbosa se refere a ela como Abordagem Triangular. Ana Mae Barbosa é hoje a principal referência do ensino da arte no Brasil. "A "Proposta Triangular" e o DBAE são interpretações diferentes, no máximo paralelas. [...] a Proposta Triangular se opõe ao DBAE, porque este disciplinariza os componentes da aprendizagem da arte, separando-os em fazer artístico, crítica de arte, estética e História da Arte, revelando, inclusive, um viés modernista na defesa implícita de um currículo desenhado por disciplinas". (BARBOSA, 1998, p. 37).
} 
A relevância da pesquisa se dá pela teorização da prática de ensino de Arte na tentativa de promover reflexões e estendê-las às situações do ensino na construção de conhecimentos proeminentes a partir de diálogos com os autores que ocupam o tema em questão. Na pesquisa em si, a valorização da prática de ensino se dá a partir da observação minuciosa do fazer artístico e narrativo dos diálogos dos discentes, organizando e dando sentido aos dados coletados.

A análise interpretativa dos dados coletados durante a pesquisa se dá a partir da organização dos padrões significativos, trabalhando seus valores culturais estéticos, escolhas artísticas, padrões visuais, oportunidades de criação e apreciações visuais.

Então, por meio dessa pesquisa, pretendo contribuir para a construção do conhecimento sustentado na experiência pedagógica do fazer no cotidiano escolar, no fruir e no fazer arte na interculturalidade em que emerge o nosso quotidiano escolar.

\section{METODOLOGIAS}

Este estudo da prática docente em Arte constituiu um estudo de caso fundado na pesquisa etnográfica de orientação qualitativo-fenomenológica. Os procedimentos de coleta e análise de dados seguem a perspectiva da observação, do registro e da reflexão por meio de narrativas. Como forma de apresentar resultados, optei pela triangulação de procedimentos uma abordagem qualitativa, uma metodologia etnográfica e método fenomenológico, resultante da observação típica de quem participam de sua prática.

O processo investigativo da própria prática de ensino, na perspectiva etnográfica, envolve relação dinâmica de reflexão sobre si e com outro no processo de apreender a sua cultura, seus significados na concepção e desenvolvimento de práticas de ensino de arte.

Procede esclarecer que o método fenomenológico nesta pesquisa busca compreender e interpretar a experiência vivida na sala de aula pelo pesquisador, direcionando a investigação para compreender o fenômeno que ocorre na prática de ensino de Arte juntamente a metodologia de ensino, de acordo com o plano de aula. Nesse caso, "a interpretação dos fenômenos que se apresentam numa sala de aula 
oferece a possibilidade de esclarecer alguns elementos culturais, como valores, que caracterizam o mundo vivido pelos sujeitos." (TRIVIÑOS, 1987, p.48).

Nesse viés, deve-se salientar que o trabalho de pesquisa aqui apresentada tem um caráter baseado nas minhas experiências de docente, mediada pelos momentos vivenciados das produções artísticas dos discentes nas relações interculturais efetivamente vividas na escola, e que a análise se implicou naturalmente ao ser narrativo ao optar por fazer uma abordagem qualitativa como forma de apresentar os nossos resultados por meio de um método misto, etnográfico e fenomenológico, resultando, dessa forma, em investigações qualitativas e fenomenológicas típicas de uma observação como participante da pesquisa.

Assim, essa metodologia se faz necessária para se auto avaliar constantemente, visando à busca de soluções para os problemas e impasses identificados durante a aplicabilidade da pesquisa, pois devem-se levar em conta as evidências da observação e da descrição, elementos cruciais da atividade etnográfica.

No experimento e na investigação surgem algumas questões problemáticas levantadas, visto que como todo o indivíduo tem o direito de uma educação de qualidade, que se observe plenamente a identidade cultural, dentro dos limites impostos pelo respeito aos direitos humanos e às liberdades fundamentais, sendo que a partir dessas colocações as problemáticas levantadas para a pesquisa foram: De que modo o professor de arte pode tornar as aulas de Arte significativas para a formação da identidade cultural do discente na proposição de buscar possibilidades criativas para trabalhar a cultura local e estética? Como o professor pode a vir a discutir a cultura local/rural no que diz a si e podendo vir a ser, a perceber de forma reflexiva o ambiente em que vive e ter significâncias para os outros discentes?

\section{PRÁTICAS}

As práticas do ensino de Arte inserem-se nas relações de espaço e tempo interrelacionadas a um contexto escolar que propicie o ensino e aprendizagem dos discentes, já predeterminadas pela sociedade estrutural, mas que se possa ser analisá-las coerentemente.

Essas práticas docentes devem partir de uma reflexão do cotidiano escolar dos discentes, e deverá se fazer presente no diário do docente de Artes, numa avaliação 
constante de análise e interpretação, isto é, ação, reflexão e ação numa prática contínua.

A proposta de intrometer-se a estudar e a pesquisar a cultura e as relações interculturais entre os discentes na prática de ensino na sala de aula proporcionou um leque de abertura de discussões e debate nas aulas de Arte, para conhecer as culturas que cada discente traz em sua bagagem sócio cultural, e como desta forma pode ser trabalhada numa proposta de interações e relações interculturais. A cultura abrange vários aspectos da vivência do homem, mas a proposta de fazer um recorte ao tema cultura, o foco será as culturas e os folclores regionais e locais vivenciados, ou mesmo "buscando-se um novo olhar" sobre aquelas culturas que eles estão vivendo, isto é, a cultura que permeia os discentes a ser trago para dentro da sala de aula para ser estudada e analisada.

Antes de conceituar a palavra cultura com os discentes, propõe-se que sua conceituação será construída e reconstruída durante todo o percurso do ensino escolar dos discentes, que ao ser pesquisado pode se dar por meio de diversos autores, ou em consulta em livros, internet ou em outros meios de registros.

A palavra cultura envolve vários conceitos determinantes para sua discussão, sendo que, a cultura contemporânea vem definindo-se por um conjunto de sentidos e práticas de ruptura com o mundo e paradigmas, objetos e artifícios; pelas fronteiras territoriais demarcadas, por linguagens próprias e discursos distintos e diversos. Neste sentido, verifica-se uma cultura em movimento acelerado conformando novas visões de mundo, novos sentidos e interpretações da realidade vivenciada por todos. Percebe-se então, que a cultura está em movimento, mudando sempre diante do mundo, talvez se possa dizer globalizado e tecnológico. Diante deste contexto, a cultura dentro do ambiente escolar passa por processo de transformação a cada momento. A expressão "cultura popular" está inserida dentro desse contexto, presente nos anseios sociais.

Diante disso, as questões a serem debatidas para abrir o diálogo com os discentes são: Quais os eventos culturais que acontecem no seu entorno, isto é, onde você vive com sua família? Quais os eventos culturais que poderiam estar presentes na região que você tem conhecimento? 
Ao perguntar sobre as questões acima, os discentes ficaram receosos e calados, às vezes, ansiosos sobre a receptividade da proposta a ser trabalhada durante $\mathrm{o}$ ano. Alguns perguntaram se teriam a proposta de desenhar nas aulas, ficando evidente que sim, pelo fato deste tema propor parte ser realizada por meio de desenhos e outras atividades instrumentais de expressões artísticas nas aulas de Arte. Ao retornar novamente nas perguntas sobre os eventos culturais que acontecem na região, para não perder o foco da discussão, os alunos ficaram mais acanhados e disseram sobre alguns eventos culturais que ocorrem na região, pois não sabiam muito, mas alguns participam desses eventos, mas não sabem suas origens, como acontecem e outras informações. Diante das discussões e debates ao tema proposto em sala de aula, os discentes falaram que são os pais, os tios, avós e vizinhos que sabem da origem desses eventos culturais. Depois de muitas discussões, foram falados os seguintes eventos culturais, como cavalgadas, cavalhadas que acontecessem no distrito de Tapuirama, Folia de reis, Festa junina e alguns já ouviram falar da Congada em Uberlândia.

Diante de tantas falas dos discentes, o evento cultural local mais desenvolvido nesta região são as cavalgadas, nas quais os discentes já participaram algumas vezes na comitiva de cavaleiros com cavalos, ou na comitiva de carros ou somente vão aos festejos acompanhando os familiares, parentes e amigos.

Entretanto, outro evento bastante comentado e discutido foi a Festa Junina que muitas vezes comemoram no mês de junho, num galpão ou no espaço da fazenda, aonde todos vão e são convidados das regiões dos fazendeiros, com traje típico caipira ou não, onde tem comida, forró, brincadeiras, fogueiras e danças. Destacaram também, que o evento da Festa Junina na escola é um momento esperado por todos, principalmente as crianças menores e os pais que gostam de ir e participar por causa dos seus filhos e parentes.

$\mathrm{Na}$ construção da Identidade cultural do discente através do desenho foi delineando a personalidade de cada um durante o percurso da aula no decorrer da aprendizagem. Esse contato com o desenho é para tentar desinibir, expressar e soltarse com o desenho. Essa busca constante da identidade cultural e para refletir sobre a vivência cultural de cada discente. 
Apesar de 'comprovar' não ser objetivo desta investigação, ratifico o quanto a pesquisa de campo é desobediente no que tange aos planos iniciais da pesquisa. Ao verificar os desenhos dos discentes percebem se a maturidade de expressividade de cada um. Diante dos dados recolhidos demonstram o caráter descritivo dessa pesquisa, mas confesso que desejava conseguir "ultrapassar os limites da palavra oral" neste momento.

Ao trabalhar com as cores dos elementos culturais, como bandeiras, lanças, vestimentas, bastões, banquetas, mastros, estandartes, fitas, e outros elementos retratam a diversidades desses elementos que compõem os movimentos culturais da região, proporciona uma riqueza de detalhes referentes a esses elementos. Nestes interesses proporciona novos olhares discentes para a cultura local e regional.

Propus ao trabalhar com as linhas coloridas com os discentes, na perspectiva da construção da forma ou não, pois conforme as conduções das discussões e debates que iam surgindo envolvendo todos na interculturalidade, e consequentemente os movimentos culturais já ditos acima propiciaram ao interesse de todos a partir desse tema.

A pesquisa dos discentes sobre esses elementos que fazem parte dos movimentos culturais proporciona pesquisa de detalhes e de observações não ficando no todo dos eventos culturais. Os detalhes poderão trazer elementos importantes para construção significativa dos movimentos culturais em si.

Outro elemento a ser pesquisado, são as cores que são utilizadas nos eventos culturais. Percebe-se que não existe um padrão de cores com seu significado, mas sim que cada "ala", "segmento", "padrão" de segmento cultural possui suas cores determinantes ou não.

A proposta de trabalhar produções artísticas a partir dos "estandartes ou bandeiras" surge a partir dos discentes na execução de colocar em prática a cultura local no qual eles vivenciavam. Os discentes despertaram o interesse nos elementos que estão presente nas Cavalgadas, Folia de Reis, Festa Junina e no Congado.

Propus que os discentes fizessem um desenho inicial, com os elementos que pertencem à cultura deles, e depois montaria os grupos, de acordo com as relações culturas mais próximas, e assim escolhessem o desenho que poderia estampar os 
"estandartes e as bandeiras". A partir foram surgindo às produções artísticas dos grupos de cada turma.

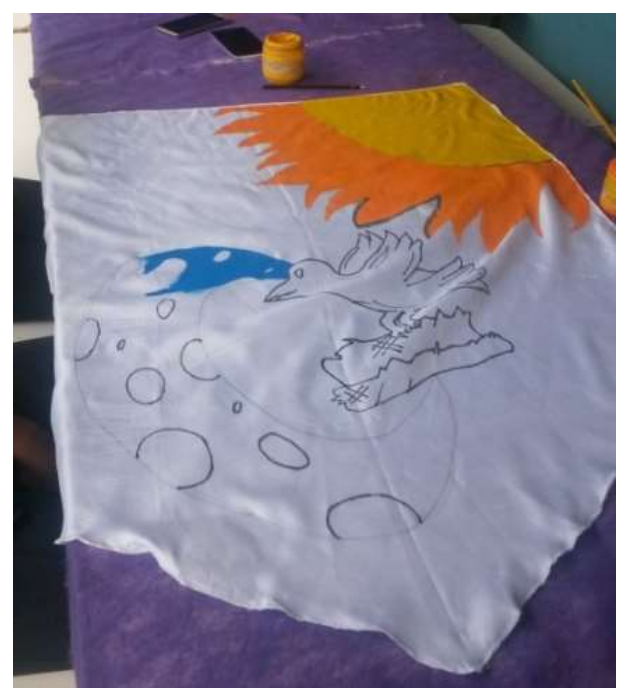

Figura 1 - Pintura dos estandartes. Alunos do $9^{\circ}$ ano da Escola Municipal Emilio Ribas, 2017, tamanho 50x95 cm, técnica guache sobre tecido. Acervo do autor Sergio Naghettini.

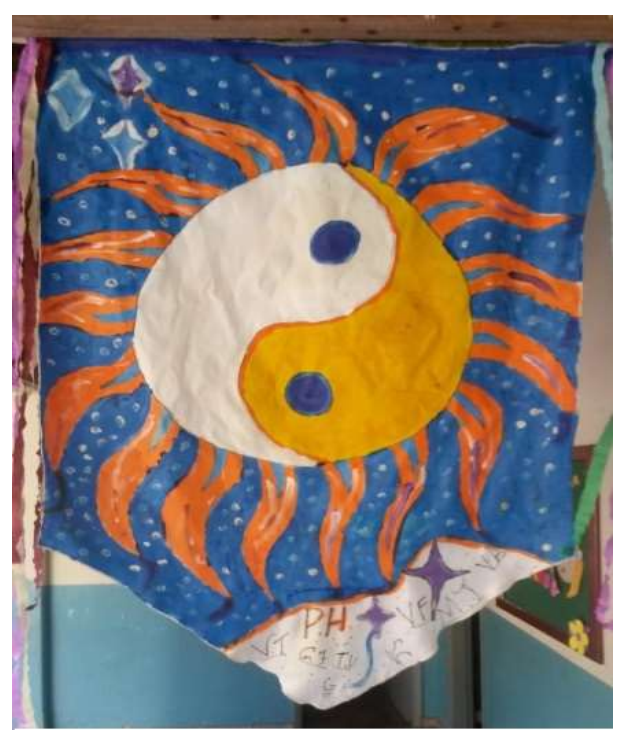

Figura 2 - Produção artística final. Alunos do $7^{a}$ ano da Escola Municipal Emilio Ribas, 2017, tamanho $50 \times 95 \mathrm{~cm}$, técnica guache sobre tecido. Acervo do autor Sérgio Naghettini. 


\section{CONSIDERAÇÕES}

Ao atuar na prática de ensino e registrá-la, percebe-se que o professor necessita se enxergar perante os alunos e às práticas pedagógicas e daí buscar novas formas de trabalhar pedagogicamente, desenvolvendo meios em que as práxis estejam associadas às atitudes diversificadas e que possa refletir e pensar sobre as atitudes como profissional da educação.

A diversidade cultural dentro da sala de aula é complexa dentro de um ambiente, principalmente na sala de aula, sendo assim, o professor de Arte poderá trabalhar aproveitando "toda a bagagem cultural" que os discentes traz na sua subjetividade nas expressões artísticas.

Acredita-se que os professores de Arte necessitam desses impulsos, de inquietações, isto é, necessita ter uma postura, inquieta e reflexiva sobre os assuntos da educação numa perspectiva de modificar as práticas e metodologias usadas no cotidiano.

\section{REFERÊNCIAS BIBLIOGRÁFICAS}

BARBOSA, Ana Mae. Tópicos utópicos. Belo Horizonte: C/Arte, 1998.

DEWEY, John. Experiência e Educação. Buenos Aires: Editorial Losada, 2010. 125p TRIVIÑOS, Augusto N. S. Introdução à pesquisa em ciências sociais. São Paulo: Atlas, 1987. 